\title{
Evaluation for Science Courses in the Middle Stage of Education in the Kingdom of Saudi Arabia Based on Light of the Next Generation Science Standards NGSS
}

\author{
Ali Saad Matar Al Harbi \\ Faculty of Education, Shaqra University, Shaqra, Saudi Arabia \\ Email: saleemdalqamoni@yahoo.com
}

How to cite this paper: Al Harbi, A.S.M. (2019) Evaluation for Science Courses in the Middle Stage of Education in the Kingdom of Saudi Arabia Based on Light of the Next Generation Science Standards NGSS. Journal of Human Resource and Sustainability Studies, 7, 160-190. https://doi.org/10.4236/jhrss.2019.72012

Received: January 7, 2019

Accepted: April 9, 2019

Published: April 12, 2019

Copyright $\odot 2019$ by author(s) and Scientific Research Publishing Inc. This work is licensed under the Creative Commons Attribution International License (CC BY 4.0).

http://creativecommons.org/licenses/by/4.0/

\begin{abstract}
The current study is aimed at evaluating the science courses in the middle stage of education in the Kingdom of Saudi Arabia in the light of the Next Generation Science Standards NGSS.
\end{abstract}

\section{Keywords}

Evaluation, Science Courses, Standards, Next Generation Science, NGSS, Kingdom of Saudi Arabia

\section{Introduction}

Societal progress lies in the science education and the empowerment of learners with scientific knowledge and its application as an indicator of civilization's progress level of societies. In this respect, it has been pointed out that the main goal of teaching science is no longer gaining the greatest amount of knowledge [1]. The most important goal is how to acquire meaningful knowledge in an exploratory form and in a way that gives learners the ability to employ and apply it in all aspects of life. It is shown that the new perspective of teaching science is the applied and functional perspective of the scientific knowledge of life environment [2]. It has also been indicated that the main goals of the contemporary science education are to equip learners with the skills that enable them to cope with life events as individuals and as citizens [3]. It is also to deal with life variables in accordance with the requirements of science and technology, locally and globally. In this respect, the researcher believes that science education is an important starting point in building strategic plans for the economic and profes- 
sional growth of societies.

The integrated approach of science education is important in science education from the perspective of the integration of science, technology, engineering, and mathematics (STEM). It was a broad-based perspective in integrating many branches of science. However, the issue that preoccupied the American society according to STEM's approach is that it is difficult to achieve the ambitious vision of the STEM framework unless there is an educational system that represents a coherent scientific approach to teach science at all the levels of education [4] [5]. The members of the National Academy of Science (NRC), National Science Teachers Association (NSTA) and the American Association for Advanced Science (AAAS), through a teamwork of 41 experts representing 26 US states developed the next generation science standards [6]. At this stage, the team proposed a framework for science education in all stages of education, from kindergarten to grade 12. The experts based this framework on the results of previous studies in the field of science education in all stages of general education, which abbreviated as the symbol K-12. The framework of science education established through four main fields: natural science, life science, earth and space science and engineering design science. The framework was completely finalized in 2011 [7]. It was followed by the introduction of the main axes of the new generation science standards. It included three dimensions:

1) In Disciplinary Core Ideas the Next Generation Science Standards depend on a specific set of ideas and practices in science. Engineering and Education is to help learners predict the variables and phenomena in their daily lives. They can evaluate and select reliable sources of scientific knowledge. The Disciplinary Core Ideas work on creating a connection between the concepts and principles so that learners are able to integrate their fully understanding of the scientific knowledge. It is used to solve the actual problems learners encounter. This dimension includes (life science, natural science, earth and space science, engineering design science). This can be of a great importance in the science and engineering disciplines. It can provide crucial interpretations of several phenomena simultaneously, generating multiple ideas to deal with problems that are relevant to the lives of learners and their expertise. These ideas are widely applicable to the field.

2) The second dimension is the scientific and engineering practices. Its aim is to develop the abilities of learners on scientific research. To redirect and promote practices related to this research. To link scientific practices to engineering practices, many variables and life situations require a clear integration between engineering practices and scientific research. These practices involve asking questions, identifying problems, developing and using models, analyzing and interpreting data, using mathematics and computational thinking, constructing interpretations, designing solutions, verifying the reliability of arguments and evidences, evaluating solutions, and transferring knowledge and employing them. 
3) The third dimension is the crosscutting concepts that focus on how to develop a systematic and consistent connection between the four disciplinary core ideas: natural science, life science, earth and space science and engineering design science. In this respect, the learner understands the interrelationships and the organizational relationships between these fields, affecting his/her understanding. They can also be able to employ this sense of life in different situations. The construction of these dimensions completed in 2013.

The education of the Next Generation Science Standards is of a great importance to those who are interested in science education. The literature considers these standards to be an unprecedented quantum leap in scientific education. They conceal the idea that science and engineering are separate entities because the three dimensions of the standards (science and engineering practices, disciplinary core ideas, and crosscutting concepts) are used simultaneously. The Next Generation Science Standards create a disciplined adjustment to link science education to reality and its problems, providing learners with the key skills to deal with the reality. Moreover, the standards make a scientific consistency of how to present concepts linking different disciplines and provide strong explanations of the relationships between them [8].

In terms of educational scientific research, the Next Generation Science Standards have witnessed a number of scientific studies, although relatively few. Some of these studies aimed at implementing teaching strategies based on the Next Generation Science Standards, such as those aimed at procedural model which provides a basis for these strategies [9]. The proposal focused on the mechanisms of learners' achievement for a future vision, to be able to deal with knowledge outside the classroom. It showed effectiveness in the development of science achievement and skills of dealing with life problems. In another study carried out showed that cause and effect as a component of the crosscutting concepts has positively affected the work of kindergarten children in the scientific projects more than the usual use of cause and effect [10]. Baz aimed at developing chemistry courses in high school, in light of the engineering design as one of the fields of the Next Generation Science Standards [11]. The results of the study indicated the weakness of the inclusion of the engineering design standards in the content of chemistry. A proposed unit designed in light of the standards of teaching science and the results of the study indicated the effectiveness of teaching the unit in the development of achieving scientific practices. For the teacher-training related studies, the results of the a study, indicated that science teachers need specific training programs to develop their skills and be prepared to teach science through the perspective of the Next Generation Science Standards [12].

In the same context, an investigation on the study on the effect of a training program based on the Next Generation Science Standards on developing investigation skills was carried out [13]. According to studies on content, the findings aimed at analyzing the content of the physics books in the Kingdom of Saudi 
Arabia regarding Next Generation Science Standards according to the energy dimension [14]. The results of the study showed that the achievement of the main dimensions in physics books at high school level were inadequate. The inclusion ratio was (33\%) and the dimension of the disciplinary core ideas were most achieved in content with an average inclusion ratio (51\%). They also showed that the inclusion ratio of the crosscutting concepts was low (31\%) whereas the inclusion ratio of the science and engineering practices was very low (16\%).

In another study of it was presented a proposed vision to develop geology as a field of the Next Generation Science Standards [15]. The results of the study indicated weakness of including three dimensions of NGSS in the field of earth science in the stages of education from primary to secondary. Some other studies adopted the conservative approach of the Next Generation Science Standards by showing that in spite of educational value of the Next Generation Science Standards, it is necessary to develop and update them periodically without regarding them as long-term standards due to changes in students' ideas and community needs [16] [17].

If the global trends of teaching science highlight the NGSS as an applied operational integrative approach to link ideas through a general framework of the education stages (K-12), the question is, do the current science courses in Saudi Arabia correlate with the new science perspective according to NGSS? The results of the previous studies indicated the lack of inclusion of the Next Generation Science Standards in the science courses. Some studies investigated one area of the standards and in a particular classroom, such as the study which investigated only energy as a subject of natural science [14]. Another study investigated only the field of earth science (geology) [15]. Also, other studies investigated the fields of genetics in biology as well as studies which targeted the field of engineering design in the first secondary grade [11] [18]. Therefore, there aren't any studies that fully investigated the verification of standards, for any of the education stages.

The researcher believes that the findings on all fields of the Next Generation Science Standards need to be in a comprehensive way. It needs to practically verify the extent of the inclusion of standards and then stating an integrated vision of development. The nature of the Next Generation Science Standards depends on the interrelationships among the different fields of science according to the perspective of the three dimensions of standards (science and engineering practices, disciplinary core ideas, and crosscutting concepts). What supports the importance of studying the development of science courses in the Kingdom of Saudi Arabia, according to Next Generation Science Standards (NGSS), despite the great efforts in preparing the current science books in cooperation with the world publisher McGraw-Hill, is the students' achievement. In which the results of the international tests such as the TIMSS test (Trends in International Mathematics and Science Study) was not at the satisfactory level. There was a decline in the overall performance of educational training courses of 2011 and 
2015. The Kingdom's rank globally, dropped from 42 to 45 . On the Arab world side, it also dropped from the second ranking to the fifth among 47 countries in the Arab World, seven of which were Arab countries. The performance gap between the two training courses was 39 points [19] [20].

The results of some studies indicated the existence of deficiencies in the current science courses related to the extrapolation of the current science books and the learners' abilities in dealing with the scientific level of their content [21]. Furthermore, other studies declared the need to develop the science courses according to the concepts of health education and the preventive education related to road and transport hazards [22] [23]. In the same context, it was indicated the need to develop the content of the science courses in the aspect of providing learners with scientific values [24]. Also, when investigating the individual differences, it was decided the need to develop the content of the science courses in accordance with the multiple and distinct intelligences of learners [25]. Generally, these aspects affect the inadequacy of learners' understanding of the scientific concepts [26].

The researcher considers that as Saudi Arabia is undergoing radical transformation based on the 2030 vision of the Kingdom, which seeks to develop industries through qualified, professional and trained workers, the Next Generation Science Standards are in line with this trend. Most of the philosophy of NGSS focuses on the mechanism of science application. Moreover, it had been pointed out that the real and meaningful employment of the scientific concepts was achieved by linking their learning to the existing industrial and technological applications in society [6].

In light of the above, it is clear that the Next Generation Science Standards (NGSS) represent a quantum leap for global science education projects and trends. In addition, these standards worked to avoid the practical problems of past trends such as the STEM approach. Therefore, it was important to verify the compatibility of science courses in Saudi Arabia with these standards especially with the rareness of studies aimed to evaluate the courses according to NGSS. Previous studies that aimed to evaluate science courses have examined one field of NGSS while the researcher discovers that working on one field of the science standards does not provide a suitable opportunity for comprehensive and in-depth insight into the extent to which the standards are included. It is worth mentioning that some previous studies worked on investigating one field of NGSS, focused only on the secondary stage while there were no studies on the middle stage which is represented as a major starting point of the formation of the learner's scientific mindset and the most skilled preparation of the specialized scientific study as well as the preparation of the learner for the future labor market skills.

This study attempted to answer the following main question: What is the evaluation of the science courses at the middle stage of education in the Kingdom of Saudi Arabia in light of the Next Generation Science Standards? Also, 
the following sub-questions were also answered:

1) What is the extent of incorporating the next generation science standards NGSS in the field of natural science in the science courses at the middle stage of education in Saudi Arabia?

2) What is the extent of incorporating the next generation science standards NGSS in the field of life science in the science courses at the middle stage of education in Saudi Arabia?

3) What is the extent of incorporating the next generation science standards NGSS in the field of earth and space science in the science courses at the middle stage of education in Saudi Arabia?

4) What is the extent of incorporating the next generation science standards NGSS in the field of engineering design in the science courses at the middle stage of education in Saudi Arabia?

5) What is the proposed vision for the development of the science courses in the middle stage of education in the Kingdom of Saudi Arabia in light of the Next Generation Science Standards NGSS?

\section{Aims of the Study}

\section{The present study is aimed to:}

1) Reveal the extent of inclusion of the Next Generation Science Standards NGSS according to the main fields that are included in the standards: natural science, life science, earth and space science, and engineering design science in the science courses at the middle stage of education in the Kingdom of Saudi Arabia.

2) Propose a practical operational vision to develop science courses in the middle stage of education in the Kingdom of Saudi Arabia in light of the Next Generation Science Standards (NGSS) based on the results of the research.

\section{Importance of the Study}

1) Providing the science curriculum designers in the Kingdom of Saudi Arabia with a scientific vision on how to develop the science courses according to a contemporary global perspective represented in the Next Generation Science Standards NGSS.

2) The focus of the directions of the Next Generation Science Standards NGSS is on educating and preparing learners and graduates for the labor market and engaging in the science and engineering practices. This approach is in line with the Kingdom's vision 2030 of the economic and transformational trends in the labor market. Hence, revealing the extent of achieving the Next Generation Science Standards represents the readiness of the current science courses to cope with the national trends of the kingdom.

3) The Next Generation Science Standards focus on the functional value of knowledge rather than on the breadth of knowledge. Therefore, the disclosure of the compatibility of the content of the science textbooks in the middle stage is 
important in dealing with some shortcomings in the current courses based on the results of studies related to the selective content of the developed science books.

4) Directing the attention of the designers of the teacher preparation programs in the faculties of education to the scientific developments that need to be included in the teaching experience of the science teachers according to the Next Generation Science Standards and the extent to which they are achieved in the current science courses.

5) The current study investigated the verification of the Next Generation Science Standards NGSS according to the four main disciplinary core ideas: natural science, life science, earth and space science, and engineering design science in the middle stage of education. This represents a great research importance because the previous studies focused only on one field. The researcher believes that the study of all the fields-despite the difficulty-represents a more accurate starting point in the judgment of the science courses content on one hand and then propose the vision of development on the other.

6) The middle stage science courses, which are the focus of the current study, are of particular importance because the learners at this stage form their tendencies and scientific orientations in a prominent way and influence the way they approach towards the future study to join the labor market. Therefore, the coincidence verification of the courses at this stage with the Next Generation Science Standards plays a vital role in the priority of development.

\section{Limitations of the Study}

1) The middle stage courses in Saudi Arabia are the targeted courses of analysis in the current study. The analysis included the textbooks and the scientific experiments booklets.

2) The analysis process of the Next Generation Science Standards was carried out according to the disciplinary core ideas that included four main fields (natural science, life science, earth and space science and engineering design science).

3) The analysis process of the Next Generation Science Standards was carried out according to the crosscutting concepts that included seven concepts (patterns, cause and effect, size-ratio-quantity, system and system models, energy and matter, structure and function, stability and change).

4) The analysis process of the Next Generation Science Standards was carried out according to the scientific and engineering practices that included eight practices. They are (asking scientific questions and engineering problems, development and use of models, planning and implementing investigations, data analysis and interpretation, using mathematics and computational thinking, build interpretations and design solutions, engage in the presentation of arguments accompanied by evidence, obtaining evaluation and exchange of information). 


\section{Approach of the Study}

The current study adopted the analytical descriptive approach in verifying the extent of inclusion of the Next Generation Science Standards NGSS according to the disciplinary core ideas: natural science, life science, earth and space science, engineering design science in the middle stage science courses in Saudi Arabia. Furthermore, the descriptive analytical approach is the most compatible with achieving the research aims and its main variables. Therefore, a practical and executive vision was suggested to develop the science courses at the middle stage in the Kingdom of Saudi Arabia in light of the Next Generation Science Standards NGSS according to the results of the extent of including these standards in the science courses.

\section{Definition of Terms}

Through reviewing the literature and related studies, the researcher defined The Next Generation Science Standards NGSS as the scientific document presented by the National Research Council (NRC) in the United States in 2013 to develop teaching science and engineering through a work plan ranging from kindergarten to the secondary stage and achieve learners' performance indicators through the interaction of the three main dimensions of standards [27] [28] [29]. First: the disciplinary core ideas and include life science, earth and space science and engineering design science. Second: the crosscutting concepts and include patterns, cause and effect, size-ratio-quantity, system and system models, energy and matter, structure and function, stability and change. Third: the scientific and engineering practices and include asking scientific questions and engineering problems, development and use of models, planning and implementing investigations, data analysis and interpretation, using mathematics and computational thinking, build interpretations and design solutions, engage in the presentation of arguments accompanied by evidence, obtaining evaluation and exchange of information.

\section{Evaluation Achievement Strategy}

The researcher analyzed the content of the science books according to the Next Generation Science Standards (NGSS). The analysis included four main areas such as: Natural Science, Life Science, Earth and Space Science and Engineering Design Science. According to three main dimensions (Science and Engineering practices, Disciplinary Core Ideas and Crosscutting concepts), a field survey was conducted to verify the validity and consistency of the analysis. The most featured results of the study are as follows:

1) The inclusion ratios of NGSS according to the natural science were $(18.63 \%$ for scientific and engineering practices, $50.13 \%$ for disciplinary core ideas, and $31.06 \%$ for crosscutting concepts).

2) The inclusion ratios of NGSS according to the life science were $(15.49 \%$ for scientific and engineering practices, $52.82 \%$ for disciplinary core ideas, and 
$31.69 \%$ for crosscutting concepts).

3) The inclusion ratios of NGSS according to the earth and space science were (16\% for scientific and engineering practices, $48 \%$ for disciplinary core ideas, and $36 \%$ for crosscutting concepts).

4) The inclusion ratios of NGSS according to the engineering design science were $(12.12 \%$ for scientific and engineering practices, $48.48 \%$ for disciplinary core ideas, and $39.39 \%$ for crosscutting concepts).

In general, the inclusion level of the scientific and engineering practices was very weak whereas the inclusion level of the disciplinary core ideas was average. The overall inclusion level of the crosscutting concepts was weak out of all the four areas of analysis. The study also presented a developmental vision in the content of science books in the middle stage of education according to the (NGSS), through three consecutive plans in the short, medium and long terms.

\section{Theoretical Framework}

The first axis: The establishment and development of the Next Generation Science Standards NGSS.

The work on the development of science education has seen many contemporary global projects and trends such as Inquiry and National Science Education Standards (2000), Learning Science in Informal Environments (2009) and Framework for K-12 Scientific Education (2011). In addition, Science, Technology, Engineering, and Mathematics (STEM) were main directions of the development of science education. Despite the educational value of this trend, it was accompanied with some problems related to the applied aspects, especially with the convictions of educators in the United States of America and the shortages in the vocational rehabilitation of learners when they join a university or engage in the labor market. This necessitated working on the development of the Next Generation Science Standards to avoid deficiencies in the previous projects and trends. Accordingly, the National Research Council (NRC) in cooperation with a group of scientific institutions including members of the National Science Teachers Association (NSTA) and the American Association for the Advanced of Science (AAAS). Through a group of experts representing a large sector of the United States decided to set new science standards NGSS [6] [7].

The work stages were as follows (Table 1):

The general formulation of the standards included:

1) A framework of the science education in all the stages of education from kindergarten to the secondary stage (A Framework for K-12 Science Education). The experts, when setting this framework, based on the results of the previous studies in the field of teaching science in all the stages of education (K-12).

2) The main dimensions of the Next Generation Science Standards included:

- The first dimension: Disciplinary Core Ideas.

- The second dimension: Science and Engineering Practices.

- The third dimension: Crosscutting Concepts (NGSS Lead, 2013). 
The second axis: The principles of the Next Generation Science Standards NGSS:

Through the researcher's review of the Next Generation Science Standards and the literature that investigated these standards, the researcher extracted the educational principles that represent the intellectual and philosophical framework of the Next Generation Science Standards as shown in Table 2 [4] [11] [17] [29]:

The third axis: The General Framework of the Next Generation Science Standards NGSS (K-12).

The team that worked on developing the framework of teaching science in all stages of education from kindergarten to grade 12 (A Framework for K-12 Science Education) aimed to achieve several main purposes:

1) Providing learners at the end of the secondary stage of education with knowledge in science, engineering, practices in disciplinary core ideas in a balanced manner to qualify them to be able to discuss issues, and scientific phenomena.

2) Providing learners with the ability to face scientific and technological problems in the various activities of life.

3) Developing the learners' skills on the continuous learning process outside the formal framework of school education.

4) Qualifying students to join careers with a strong interest in science, engineering and technology.

5) Developing the learner's appreciation of science and the accumulated efforts of scientists to develop and update knowledge [29] [30].

The fourth axis: The dimensions of the Next Generation Science Standards NGSS.

Table 1. Work stages.

\begin{tabular}{lll}
\hline Stage \# & Description & Date \\
\hline One & $\begin{array}{l}\text { The number of states participated in the } \\
\text { project was (26) and the number of experts was (41). }\end{array}$ & Summer of 2011 \\
Two & $\begin{array}{l}\text { The first draft of the Next Generation Science } \\
\text { Standards NGSS was issued by the teamwork. }\end{array}$ & Fall of 2011 \\
Three & The experts reviewed the first draft. & \\
Four & A panel of jury members reviewed the first draft. & \\
& The first formulation of the Next Generation Science Standards & June 2012 \\
Five & NGSS was issued and published to the teachers to make their & \\
& comments. & \\
Six & The second revised formulation of the Next Generation Science & \\
& Standards NGSS was issued and published to the interested & January 2013 \\
parties to receive their comments. & \\
\hline
\end{tabular}

(The Next Generation Science Standards, 2014). 
Table 2. Abstract of the general principles of the Next Generation Science Standards NGSS.

\begin{tabular}{|c|c|}
\hline Principle & Description of principle \\
\hline $\begin{array}{l}\text { A new offering related to the } \\
\text { educational privacy }\end{array}$ & $\begin{array}{l}\text { The Next Generation Science Standards (NGSS) represent an } \\
\text { integrated educational vision for education, recognize the specific } \\
\text { standards of each educational state and connect them with } \\
\text { appropriate adaptations that give the prospect of transferring } \\
\text { standards across different cultures. }\end{array}$ \\
\hline Priority performance & $\begin{array}{l}\text { The Next Generation Science Standards (NGSS) tried to avoid } \\
\text { project problems and past trends by focusing on student } \\
\text { performance expectations rather than expanding the academic } \\
\text { content. }\end{array}$ \\
\hline Broad methodological vision & $\begin{array}{l}\text { The Next Generation Science Standards (NGSS) worked on } \\
\text { developing a systematic integrated approach from kindergarten } \\
\text { to the secondary stage of education rather than offering a } \\
\text { theoretical philosophy. }\end{array}$ \\
\hline $\begin{array}{l}\text { Integration of ideas with } \\
\text { implementation mechanisms }\end{array}$ & $\begin{array}{l}\text { The Next Generation Science Standards (NGSS) aimed to } \\
\text { introduce a systematic perspective through the K-12 framework } \\
\text { and clarify the mechanism in which the three pillars (disciplinary } \\
\text { core ideas-science and engineering practices-crosscutting } \\
\text { concepts) deal with how the framework is implemented. }\end{array}$ \\
\hline Training & $\begin{array}{l}\text { The Next Generation Science Standards (NGSS) were designed } \\
\text { to prepare students for a specialized university study providing } \\
\text { them with the opportunity to be trained in the future by } \\
\text { acquiring solid scientific and engineering practices that have } \\
\text { been worked on since childhood. }\end{array}$ \\
\hline Integration & $\begin{array}{l}\text { The Next Generation Science Standards (NGSS) aim to build a } \\
\text { common area of science-engineering linking through an applied } \\
\text { perspective, so that the integration process is realistic not } \\
\text { artificial, from an academic perspective. }\end{array}$ \\
\hline Selection & $\begin{array}{l}\text { The Next Generation Science Standards (NGSS) focus on } \\
\text { providing the learner with the ability to have a deep } \\
\text { understanding of knowledge with the form in which he/she can } \\
\text { function. This requires some kind of selection of knowledge that } \\
\text { is provided with a functional and practical value. }\end{array}$ \\
\hline
\end{tabular}

The Next Generation Science Standards were based on a general framework for teaching science from kindergarten until the secondary stage (K-12). These standards include a work mechanism between the three dimensions that work in an interrelated and consistent manner. These are:

1) Scientific and Engineering Practices (SEPs)

The scientific and engineering practices refer to the behavior in which the specialists in scientific research work on, and the verification of the scientific phenomena and studying them through different models and experiments.

In general, the Next Generation Science Standards NGSS presented eight practices that reflected the general framework of the science and engineering practices:

a) Asking scientific questions and engineering problems.

b) Development and use of models.

c) Planning and implementing investigations. 
d) Data analysis and interpretation.

e) Using mathematics and computational thinking.

f) Build interpretations and design solutions.

g) Engage in the presentation of arguments accompanied by evidence.

h) Obtaining, evaluation and exchange of information.

2) Crosscutting Concepts (CCCs)

Crosscutting concepts are a powerful mechanism of linking different branches of knowledge. Thus, they can be considered as tools that help the learner to think and connect different branches of knowledge and use them in various broad applications based on knowledge from diverse sciences. The educational values of crosscutting concepts according to the Next Generation Science Standards are as follows [14] [15] [16]:

a) Crosscutting concepts support in-depth understanding of science and engineering practices simultaneously.

b) Crosscutting concepts allow horizontal and vertical linkage of knowledge growth across successive classrooms.

c) Crosscutting concepts fit different patterns of learners.

d) Crosscutting concepts enrich a clearer understanding of the complementary main ideas between science and mathematics in particular.

e) Crosscutting concepts lead to a kind of learner's familiarity in different branches of knowledge without worrying about the differences between them.

3) Disciplinary Core Ideas (DCLCs)

Next Generation Science Standards (NGSS) focus on the quality of content that is selective and focusing on the link between science and engineering on one hand and the functional application value on the other. The term is not a study of a large number of topics, which may eventually lead to separate academic entities. The main ideas of the Next Generation Science Standards include four main disciplinary core ideas extending through the general education stages (K-12) as follows:

a) Field 1: Physics.

b) Field 2: Life science.

c) Field 3: Earth and space science.

d) Field 4: Engineering design science.

In general, the standards of selecting the areas that represent the central themes and their sub-themes in the work plan (K-12) were:

- The first standard: (Disciplinary core ideas represent the tools of thinking) through which the sub-components are connected, so the learner can perceive the relationships between these components as a starting point to deal with life problems.

- The second standard: (Correlation) each idea is formed of a series of subjects and is coherent in the educational stage of the learners. Each idea of the Next Generation Science Standards extends from childhood to secondary school.

- The third standard: (Broadening) each idea of disciplinary core ideas in- 
cludes sub-topics in a comprehensive manner in which the core idea has a clear independence of knowledge of other ideas.

- The fourth standard: (Capability) each idea raised from the perspective of applicability in the life experiences of the learner because the ideas are presented in a longitudinal way through the stages of public education in K-12 [6] [7] [29] [30].

Through the researcher's extrapolating to the three main dimensions of the Next Generation Science Standards, it is possible to develop a representative scenario that summarizes the relationship between these dimensions through the following diagram (Figure 1).

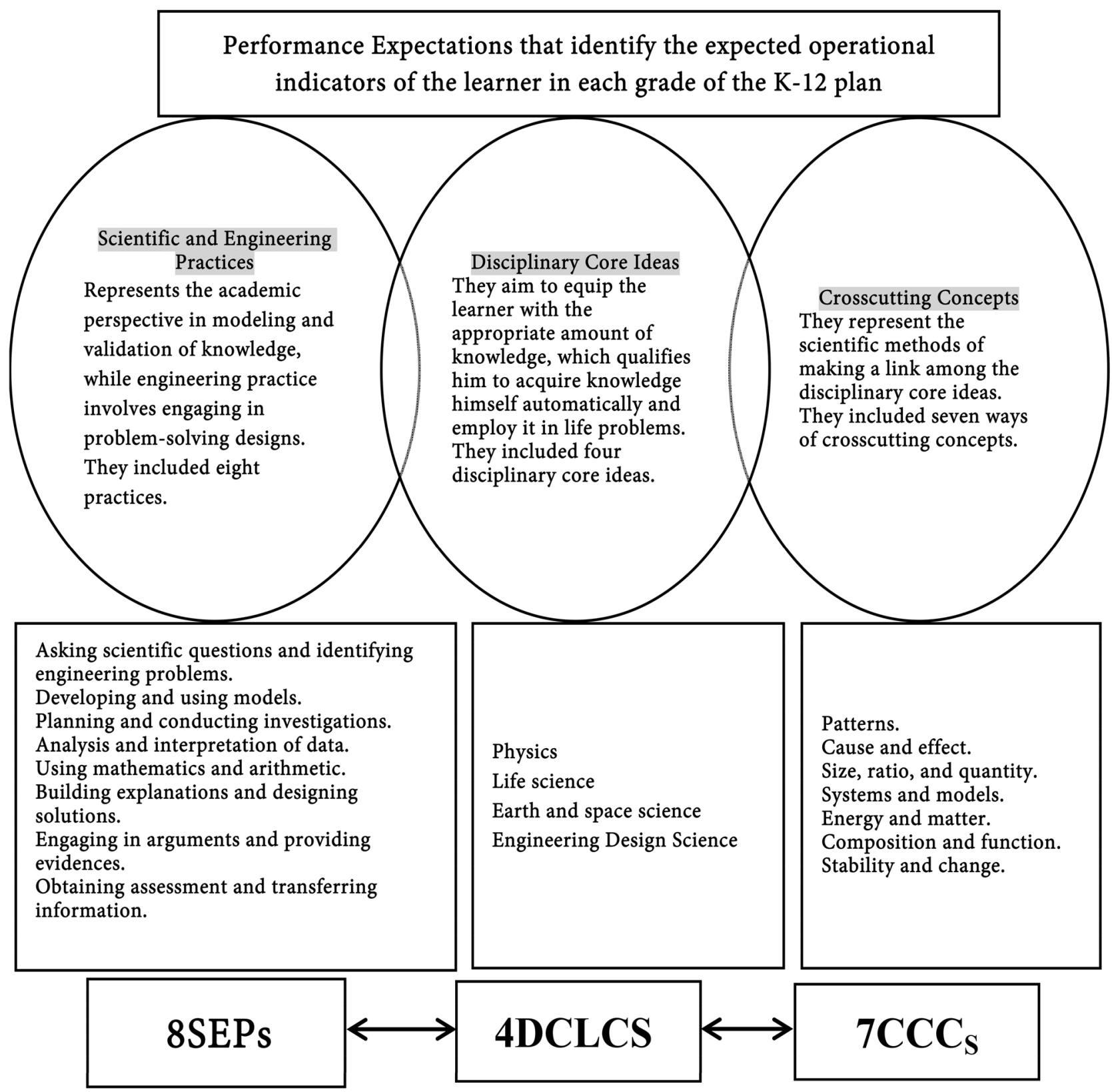

Figure 1. Relationship between NGSS dimensions. 
The fifth axis: Educational value of the Next Generation Science Standards.

Many contemporary global projects and trends proposed the Next Generation Science Standards, such as the Inquiry and National Science Education Standards in 2000, Science Learning Science in Informal Environments in 2009 and the framework K-12 for Science Education in 2011. Also, Science, Technology, Engineering, and Mathematics (STEM) were most prominent hese trends [4] [5] [9] [31] [32]. In this respect, the researcher highlighted the above in the theoretical framework of the Next Generation Science Standards through a review of the literature to draw aspects of excellence of the Next Generation Science Standards compared to previous trends and projects to develop the teaching of science as shown in the following scheme [14] [15] [18] (Figure 2).

Field of the Study

The scientific content of the science textbooks at the middle stage of education was analyzed in the light of the Next Generation Science Standards (NGSS) according to the following procedural steps:

1) Objective of the analysis: The objective of the analysis is to determine the extent to which NGSS is included in the four main areas: natural science, space science, earth, life science and engineering design science.

2) Determining the categories of analysis: The analysis category was presented in the scientific standards that were included in the Next Generation Science Standards NGSS. The structural nature of the Next Generation Science Standards is based on the standards that represent the expected performance indicators from the learner. These standards are based on the three main dimensions: disciplinary core ideas, science and engineering practices, and crosscutting concepts, as indicated in the theoretical framework of the current study.

3) Determination of the units of analysis: The unit of analysis of the lesson represented the appropriate structural unit of the analysis of the science books divided into academic years and semesters. The content of each semester included a set of units divided into chapters and lessons (Table 3).

4) Verification of the validity of the analysis: The analysis form was presented to a panel of jury members in order to check the accuracy of the form taxonomy according to the structure of the Next Generation Science Standards. Due to the difficulty of the task, the analysis of each of the four fields was presented to three jury members independently.

5) Verification of the stability of the analysis: Four senior teachers with more than ten years of experience worked on analyzing the same courses that the researcher did according to the Next Generation Science Standards to check the stability. To achieve the stability, the researcher used the Richardson equation of stability coefficient $=(2 \times$ total values agreed by analysts $)$ divided by the sum of the values of the first analyst (a) + the sum of the values of the second analyst (b) and therefore the results of the stability of the analysis are as shown in Table 4. 
Table 3. Analysis distribution of the middle stage courses according to the Next Generation Science Standards (NGSS).

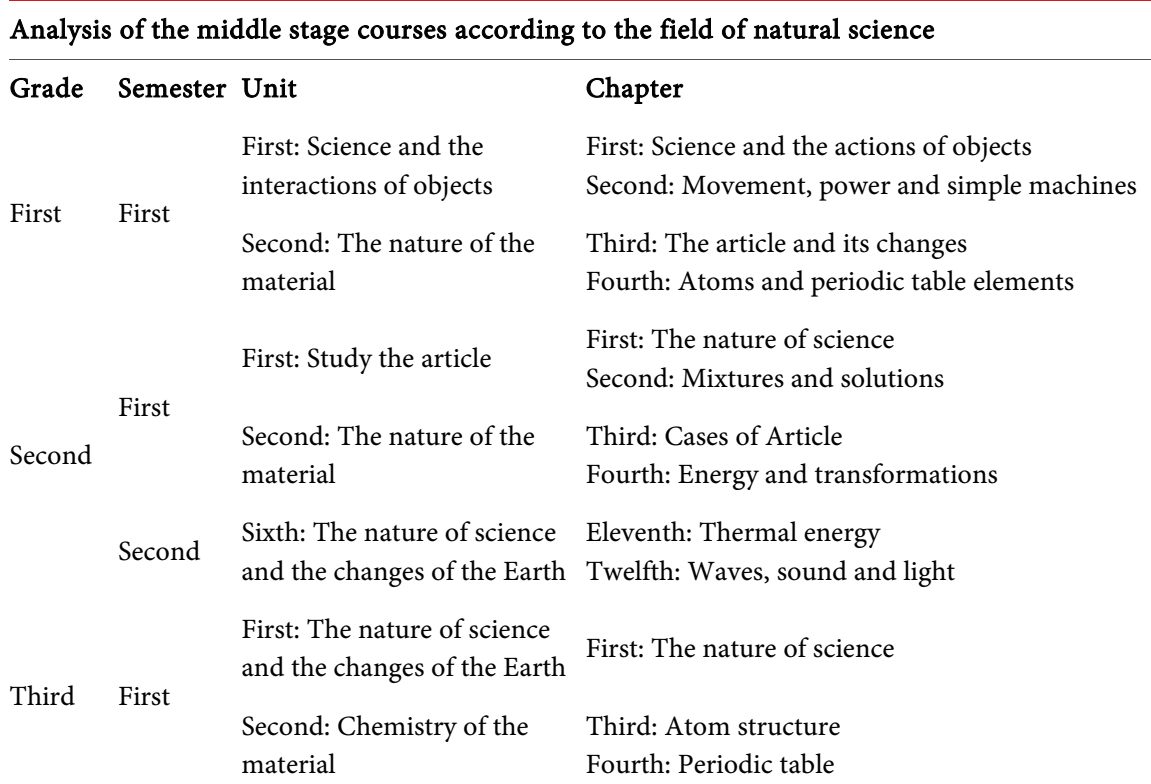

Analysis of middle stage courses according to the field of natural science

$\begin{array}{lll}\begin{array}{l}\text { Third: Chemical bonds and } \\ \text { reactions }\end{array} & \begin{array}{l}\text { Fifth: Atomic construction and } \\ \text { chemical bonds } \\ \text { Sixth: Chemical reactions }\end{array} \\ \text { Second } & \begin{array}{l}\text { Fifth: The movement and } \\ \text { power }\end{array} & \begin{array}{l}\text { Ninth: Motion and momentum } \\ \text { Tenth: Power and Newton's laws }\end{array} \\ & \begin{array}{l}\text { Sixth: Electricity and } \\ \text { Magnetism }\end{array} & \begin{array}{l}\text { Eleventh: Electricity } \\ \text { Twelfth: Magnetism }\end{array}\end{array}$

Analysis of the middle stage courses according to the field of earth and space science

\begin{tabular}{|c|c|c|c|}
\hline Grade & Semester & Unit & Chapter \\
\hline First & First & $\begin{array}{l}\text { Third: the varied surface of } \\
\text { earth }\end{array}$ & $\begin{array}{l}\text { Fifth: Rocks and minerals } \\
\text { Sixth: The formation forces of Earth }\end{array}$ \\
\hline Third & First & $\begin{array}{l}\text { First: the nature of science } \\
\text { and Earth changes }\end{array}$ & Second: Earth changes \\
\hline \multicolumn{4}{|c|}{ Analysis of the middle stage courses according to the field of life science } \\
\hline Grade & Semester & Unit & Chapter \\
\hline \multirow[t]{2}{*}{ First } & \multirow[t]{2}{*}{ Second } & Fifth: Life variation & $\begin{array}{l}\text { Ninth: Cells are living blocks } \\
\text { Tenth: Invertebrate animals } \\
\text { Eleven: Vertebrate animals }\end{array}$ \\
\hline & & $\begin{array}{l}\text { Sixth: Life and } \\
\text { environment }\end{array}$ & $\begin{array}{l}\text { Twelfth: Ecology } \\
\text { Thirteenth: Land resources }\end{array}$ \\
\hline \multirow{3}{*}{ Second } & First & $\begin{array}{l}\text { Third: Human body } \\
\text { organs }\end{array}$ & $\begin{array}{l}\text { Fifth: The circulatory system and immunity } \\
\text { Sixth: Digestion, breathing and excretion }\end{array}$ \\
\hline & \multirow{2}{*}{ Second } & Fourth: Human body organs & $\begin{array}{l}\text { Seventh: The devices of movement support and } \\
\text { response } \\
\text { Eighth: Regulation and Reproduction }\end{array}$ \\
\hline & & $\begin{array}{l}\text { Fifth: Plants and } \\
\text { environment resources }\end{array}$ & $\begin{array}{l}\text { Ninth: Plant } \\
\text { Tenth: Environmental resources and protection }\end{array}$ \\
\hline
\end{tabular}




\section{Continued}

Third Second Fourth: Foundations of life Seventh: Cell activities and processes

Eighth: Genetics

Analysis of middle stage courses according to the field of engineering design science

The analysis of the content included all the science books of the three grades of the middle stage of education.

Table 4. Results of stability verification of the analysis of the science books in the middle stage of education.

\begin{tabular}{cc}
\hline Field of analysis according to NGSS & Stability coefficient \\
\hline Field of Natural Science & 0.88 \\
Field of Earth and Space Science & 0.85 \\
Field of Life Science & 0.91 \\
Field of Engineering Design & 0.87 \\
Fields as a whole & 0.88
\end{tabular}

\begin{tabular}{|c|c|c|c|}
\hline \multicolumn{2}{|c|}{$\begin{array}{l}\text { Economic Vision } \\
\text { The next generation science standards have } \\
\text { crossed the usual academic boundaries, } \\
\text { addressing the rehabilitation of learners to the } \\
\text { labor market and engaging in dealing with prob- } \\
\text { lems and phenomena in the real environment. }\end{array}$} & \multicolumn{2}{|c|}{$\begin{array}{l}\text { Future vision } \\
\text { The next generation science standards provided } \\
\text { an in-depth insight into the 21st century's data } \\
\text { and variables by focusing on dealing with issues } \\
\text { and problems through science and engineering } \\
\text { practices rather than focusing on the usual skills. }\end{array}$} \\
\hline $\begin{array}{l}\text { Reform vision } \\
\text { The next generation science } \\
\text { standards extended to the results of } \\
\text { previous studies and trends through a } \\
\text { reform vision to overcome difficulties } \\
\text { and shortcomings }\end{array}$ & \multicolumn{2}{|c|}{$\begin{array}{c}\text { Educational value } \\
\text { of the Next } \\
\text { Generation Science } \\
\text { Standards }\end{array}$} & $\begin{array}{l}\quad \text { The overall vision } \\
\text { The next generation science } \\
\text { standards have extended to all } \\
\text { classes of ordinary, talented, } \\
\text { high-quality students as well as } \\
\text { learning disabilities. }\end{array}$ \\
\hline \multicolumn{2}{|c|}{$\begin{array}{l}\text { Standard Vision } \\
\text { The next generation science standards focused } \\
\text { on the learner's performance expectations and } \\
\text { achievement indicators as standards to verify } \\
\text { achievement of goals. This orientation is } \\
\text { particularly valuable because it is based on } \\
\text { learner-specific standards rather than on the } \\
\text { nature of the content. }\end{array}$} & $\begin{array}{l}\text { The nex } \\
\text { not me } \\
\text { perspec } \\
\text { executi } \\
\text { mechan } \\
\text { commo } \\
\text { practice } \\
\text { learner } \\
\text { from ki }\end{array}$ & $\begin{array}{l}\text { Executive vision } \\
\text { eneration science standards are } \\
\text { a philosophical and instructional } \\
\text { of teaching science but an } \\
\text { rientation because it provided } \\
\text { s to link the central concepts to the } \\
\text { oncepts of the scientific engineering } \\
\text { ith the performance expectations of } \\
\text { id through a rigorous curriculum } \\
\text { rgarten to secondary school stage. }\end{array}$ \\
\hline
\end{tabular}

Figure 2. Proposed scheme of the educational value of the next generation science standards.

According to the results in Table 3 and the analytical procedures of the science books in the middle stage, the scientific analysis followed by the researcher can be trusted and the results are accepted.

6) The inclusion ratios of the Next Generation Science Standards were explained according to the following distribution:

- Inclusion ratio from $0 \%$ to less than $20 \%$ represents a very weak inclusion.

- Inclusion ratio from $20 \%$ to less than $40 \%$ is a weak inclusion. 
- Inclusion ratio of $40 \%$ to less than $60 \%$ represents the average inclusion.

- Inclusion ratio from $60 \%$ to less than $80 \%$ represents high inclusion.

- Inclusion ratio of $80 \%$ to $100 \%$ represents a very high inclusion.

\section{Study Results, Discussion and Interpretation}

\section{Answer to the first question of the study:}

The first question of the study is: What is the extent of incorporating the next generation science standards NGSS in the field of natural science in the science courses at the middle stage of education in Saudi Arabia? To answer this question, the researcher conducted an analysis of the content of science books in the middle stage of education according to the target units of the field of natural science. The following remarks from this show:

1) The frequency of NGSS according to the natural science in the middle stage courses as a whole was 161 times and was distributed as follows: 30 times for science and engineering practices, 81 times for disciplinary core ideas, 50 times for crosscutting concepts. This indicated that the inclusion ratios of these dimensions were respectively $(18.63 \%, 50.13 \%$, and $31.06 \%)$, as shown in Figure 3:

2) Inclusion ratios achieved by the three dimensions of the Next Generation Science Standards (NGSS) according to the natural science in middle stage courses indicated that the inclusion of standards of the science and engineering practices was very weak and the inclusion standards of the disciplinary core ideas was average whereas the inclusion of the standards of the crosscutting concepts was weak. According to these results, it can be concluded that the frequency of NGSS of the natural science in the middle stage courses was generally simple. Most of the focus achieved in the standards of disciplinary core ideas, less in crosscutting concepts and seemed to be weak in the science and engineering practices. The results reflect the fact that the nature of the content of the current science courses in relation to natural sciences focuses on content and investigation rather than the learner's ability to provide thinking tools, practical application practices to deal with life problems, and to provide comprehensive thinking tools for the main concepts in dealing with natural sciences.

3) Inclusion ratios of standards in the scientific and engineering practices were as follows:

- Asking questions and identifying problems (6.67\%).

- Development and using models (6.67\%).

- Planning and implementing investigations (20\%).

- Data analysis and interpretation (20\%).

- Using Mathematics and Computational Thinking (10\%).

- Building interpretations and designing solutions (10\%).

- Engaging in the presentation of arguments accompanied by evidence (13.33\%).

- Obtaining, evaluation and exchange of information (13.33\%).

These ratios showed that the less common practices were the development 


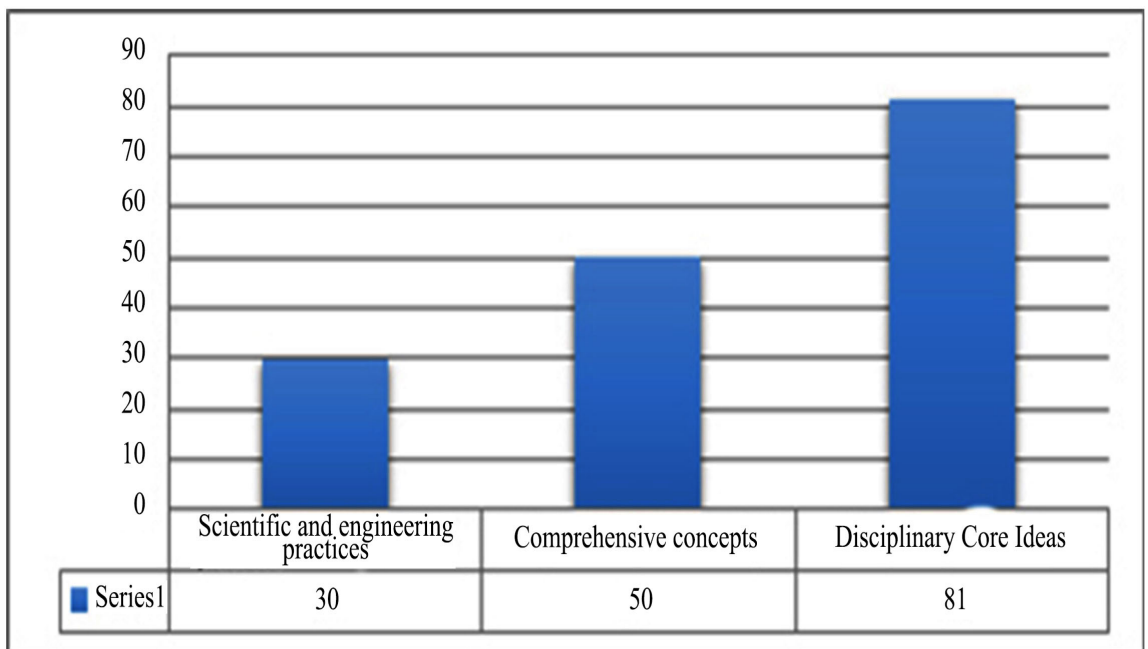

Figure 3. Frequency distribution of the Next Generation Science Standards NGSS according to the field of natural science in the science courses in the middle stage.

and use of models, while the most common standards were in the analysis and interpretation of data and the survey followed by the conduct of experiments. This means that the more advanced scientific and engineering practices that represent an actual simulation of the work of engineers were the least included.

4) Inclusion ratios of standards in the disciplinary core ideas were as follows:

- Structure and properties of the matter (25.93\%).

- Chemical reactions (12.35\%).

- Definition of energy (13.58\%).

- Forces and movement (2.47\%).

- Types of forces $(9.88 \%)$.

- Energy transmission and energy conservation law (11.11\%).

- The relationship between energy and force (3.70\%).

- Characteristics of waves (7.41\%).

- Electromagnetic spectrum (11.11\%).

- Information Technology (2.47\%).

The inclusion ratios of standards in the disciplinary core ideas in natural sciences showed that there was no balance in including these standards. There was a high degree of inclusion in the structure and properties of the matter, while there was a lack of inclusion in the standards of forces and movement, the relationship between energy and forces and information technology.

5) Inclusion rates of standards in the crosscutting concepts were as follows:

- Use of patterns (6\%).

- Cause and effect (18\%).

- Energy and matter (26\%).

- Systems and system models (14\%).

- Structure and function (16\%).

- Stability and change (4\%).

- Quantity, volume and ratio (16\%). 
The inclusion ratios of standards in the crosscutting concepts indicated that there was no strong balance in the distribution of these standards. There was a greater degree of inclusion of energy, matter, cause and effect standards, while the inclusion of standards of stability and change and use of patterns was less reflected. Science courses in the middle stage are concerned with the usual mechanisms to highlight the functions of elements according to their components. The learner is able to think less about the formation of concepts and public relations to connect different elements and components.

\section{Answer to the second question of the study:}

The second question of the study is: What is the extent of incorporating the next generation science standards NGSS in the field of life science in the science courses at the middle stage of education in Saudi Arabia? To answer this question, the researcher conducted an analysis of the content of science books in the middle stage according to the units targeted in the field of life sciences, as the summarized results show the following:

1) The frequency of the NGSS of life science in the middle stage as a whole was 142 times and was distributed as follows: 22 times for scientific and engineering practices, 75 times for disciplinary core ideas, and 45 times for crosscutting concepts. This indicated that the inclusion ratios of these dimensions were respectively (15.49\% and 52.82\%, 31.69\%), as shown in Figure 4:

2) The included ratios achieved by the three dimensions of NGSS of life science in the middle stage courses indicated that the inclusion of standards in the scientific and engineering practices was very weak. The inclusion of standards in the disciplinary core ideas was intermediate and the inclusion of standards in the crosscutting concepts was weak. These results showed that the frequency of NGSS for life science in the middle stage courses was generally simple. The greater inclusion of the standards was clearer in the standards of the disciplinary core ideas whereas the inclusion was less in the crosscutting concepts. The results reflected the fact that the nature of the current science textbooks content according to the life science focused more on the content and inquiry than providing the learner with the thinking tools, applied practical practices to deal with life problems, and comprehensive thinking tools for the main concepts in dealing with life science.

3) Inclusion ratios of standards in the science and engineering practices were as follows.

- Asking scientific questions and identifying problems (9.09\%).

- Development and use of models (13.64\%).

- Planning and implementing investigations (9.09\%).

- Data analysis and interpretation (18.18\%).

- Using mathematics and computational thinking (4.55\%).

- Building interpretations and design solutions (27.27\%).

- Engaging in the presentation of arguments accompanied by evidence $(9.09 \%)$.

- Obtaining evaluation and exchange of information (9.09\%). 




Figure 4. Frequency distribution of the Next Generation Science Standards NGSS according to the field of life science in science courses in the middle stage of education.

These ratios indicated that the less common practice was using mathematics and computational thinking while the most common standard was building interpretations and designing solutions, followed by the analysis and interpretation of data. This means that science and engineering practices in life science did not focus on applications of a normative nature where mathematics and computational thinking are required in use in law and relationship-related applications.

4) The inclusion ratios of standards in the disciplinary core ideas were as follows:

- Structure and function (20\%).

- Growth and evolution of living organisms (13.33\%).

- Kinetics of matter and energy in living organisms (9.33\%).

- Information processing (4\%).

- Chemical reactions and energy in life (4\%).

- Interrelationships in ecosystems (10.67\%).

- Material and energy transfer cycles in ecosystems (2.67\%).

- Dynamics of ecosystems (5.33\%).

- Biodiversity and human (2.67\%).

- Reproduction (25.93\%).

- Genetic traits (4\%).

- Genetic variation (6.67\%).

- Evidence on the fossil record and evolution of living organisms (5.33\%).

- Natural selection (4\%).

- Adaptation (2.67\%).

The ratios of the included standards of the disciplinary core ideas in the natural science were unbalanced in incorporating them since there was a high degree of inclusion for the composition and function while there was a lack of inclusion in the standards for adaptation and natural selection.

5) The inclusion rates of standards in the crosscutting concepts were as follows: 
- Using patterns (20\%),

- Cause and effect (42.22\%).

- Energy and material (11.11\%).

- Systems and system models (4.44\%).

- Structure and function (8.89\%).

- Stability and change (8.89\%).

- Quantity, size and ratio (4.44\%).

In the distribution of inclusion ratios, there was no consistent balance in the distribution of these standards. There was a greater degree of standards for the pattern use, cause and effect, while the inclusion of the standards for quantity, size, and ratio, stability and change was less. This agreed with the standards of the scientific and engineering practices, which reduced the use of mathematics and computational thinking, reflecting the fact that the nature of the field of life science focused on theoretical inquiry.

\section{Answer to the third question of the study:}

The third question of the study is: What is the extent of incorporating the next generation science standards NGSS in the field of earth and space science in the science courses at the middle stage of education in Saudi Arabia?

To answer this question, the researcher analyzed the content of the science books in the middle stage according to the targeted units of the field of earth and space science. The data collected from the research showed the following:

1) According to the ratios of inclusion of the three dimensions, it was clear that the frequency of NGSS in the field of earth and space science in middle stage as a whole was 50 times and distributed as follows: 8 for scientific and engineering practices, 24 for the disciplinary core ideas, and 18 for the crosscutting concepts, meaning that the proportions of these dimensions were respectively $(16 \%, 48 \%, 36 \%)$, as shown in Figure 5.

2) Inclusion ratios achieved by the three dimensions of NGSS of earth and space science in the middle stage courses means that the inclusion of the standards of the scientific and engineering practices was very weak. The inclusion of the standards of the disciplinary core ideas was average while the inclusion of the standards of the crosscutting concepts was weak. Thus, the overall results of the NGSS of the earth and space science shown to be relatively simple in the middle stage.

The greatest inclusion of the standards based on the standards of the disciplinary core ideas while the inclusion was less in the crosscutting concepts. These results reflected the fact that the nature of the content of the current science textbooks according to earth and space science gave great importance to cognitive content provided to learners. It raised the academic value mixed with exploratory thinking, while the Next Generation Science Standards gave a greater value to the nature of the learner's practices in applications and problems of life based on academic knowledge and skills. 


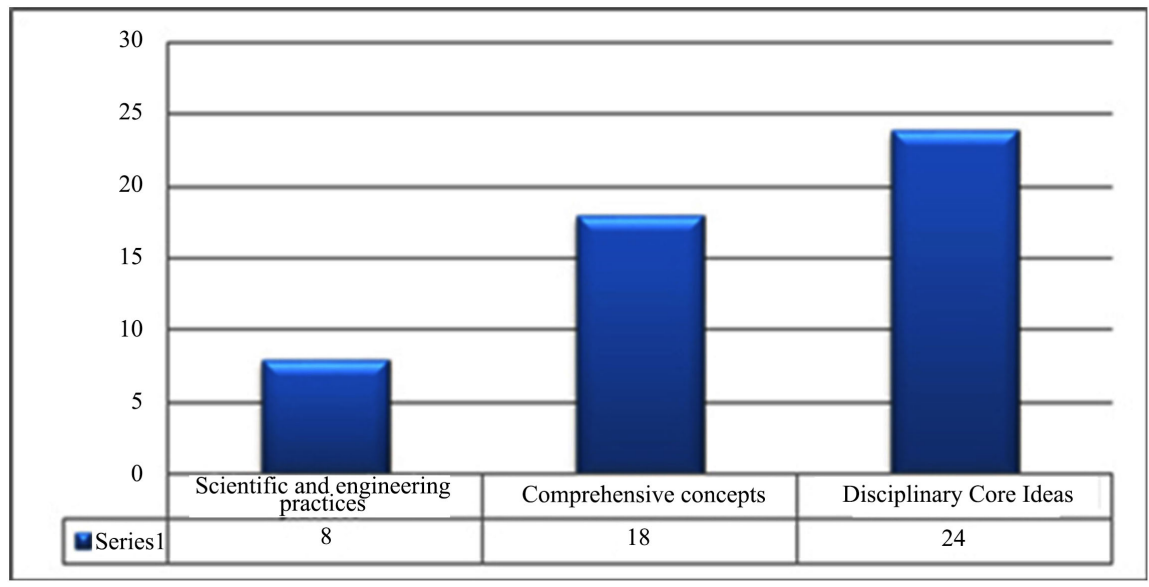

Figure 5. Frequency distribution of the Next Generation Science Standards NGSS in the science courses at middle stage in the field of earth and space science.

3) Inclusion ratios of standards in the scientific and engineering practices were as follows:

- Asking questions and identifying problems (12.5\%).

- Developing and using models (25\%).

- Planning and implementing investigations (12.5\%).

- Data analysis and interpretation (25\%).

- Building explanations and designing solutions (12.5\%).

- Engaging in the presentation of arguments accompanied with evidence (25\%).

The less common standards utilized for developing and using models were planning and implementing investigations, building interpretations and designing solutions, and asking questions and identifying problems. On the other hand, the most common standards were for developing and using models, data analysis and interpretation data and Engaging in the presentation of arguments accompanied with evidence. The field of earth and space science did not focus on applications of a practical nature or the use of technology to acquire and manipulate knowledge.

4) The inclusion ratios of standards in the disciplinary core ideas were as follows:

- Universe and galaxies (12.50\%).

- Earth and solar system (12.50\%).

- History of the Earth (8.34\%).

- Resources and systems on Earth (12.50\%).

- Movement of tectonic plates (4.17\%).

- Water cycle on Earth (12.50\%).

- Natural disasters (12.5\%).

- The impact of human activity on Earth (8.34\%).

- Weather and climate (12.5\%).

- Natural resources (4.17\%). 
It is clear from the distribution of these ratios that the rates of inclusion of the standards of the disciplinary core ideas in the field of earth and space science were acceptable to the balanced distribution. They included the standards of (universe and galaxies, earth and the solar system, resources and systems, weather and climate, and the water cycle on the earth's surface), while there was a decline in the inclusion of standards (tectonic plate movement and natural resources).

5) The inclusion ratios of standards in the crosscutting concepts were as follows:

- Pattern use (16.68\%).

- Cause and effect (38.90\%).

- Energy and material (11.12\%).

- Systems and system models (11.12\%).

- Structure and function (5.56\%).

- Stability and change (5.56\%).

- Quantity, size and ratio (11.12\%).

There was a greater degree of cause and effect and using patterns, followed by the same ratios of special parameters such as energy and material, systems and system models, quantity, size and ratio. In addition, the standards of structure and function, and stability and change were reduced although the standards of these concepts were expected to be more inclusive according to the field of earth and space science.

Answer to the fourth question of the study:

The fourth question of the study is: What is the extent of incorporating the next generation science standards NGSS in the field of engineering design science in the science courses at the middle stage of education in Saudi Arabia? To answer this question, the researcher conducted an analysis of the content of the science books in the middle stage according to the units of engineering design science as a disciplinary core idea. The results were as shown in Table 5 .

The data in the previous table showed the following:

1) According to the inclusion of the three dimensions, it was clear that the frequency of the NGSS for the engineering design science in middle stage as a whole was 33 times and distributed as follows: 4 for the scientific and engineering practices, 13 for the disciplinary core ideas, and 16 times for the crosscutting concepts, meaning that the ratios of these dimensions were respectively $(12.12 \%$, $39.39 \%, 48.48 \%$ ) as shown in Figure 6.

2) Inclusion ratios achieved by the three dimensions of NGSS for engineering design science in the middle stage courses mean that the inclusion of the standards of scientific and engineering practices was very weak. The inclusion of the standards of the disciplinary core ideas was average whereas the inclusion of the standards of the crosscutting concepts was weak. Thus, the overall results of the NGSS for the engineering design science are generally very simple in the middle 
Table 5. Results of the analysis of the middle stage courses content according to the Next Generation Science Standards NGSS in the field of engineering design science.

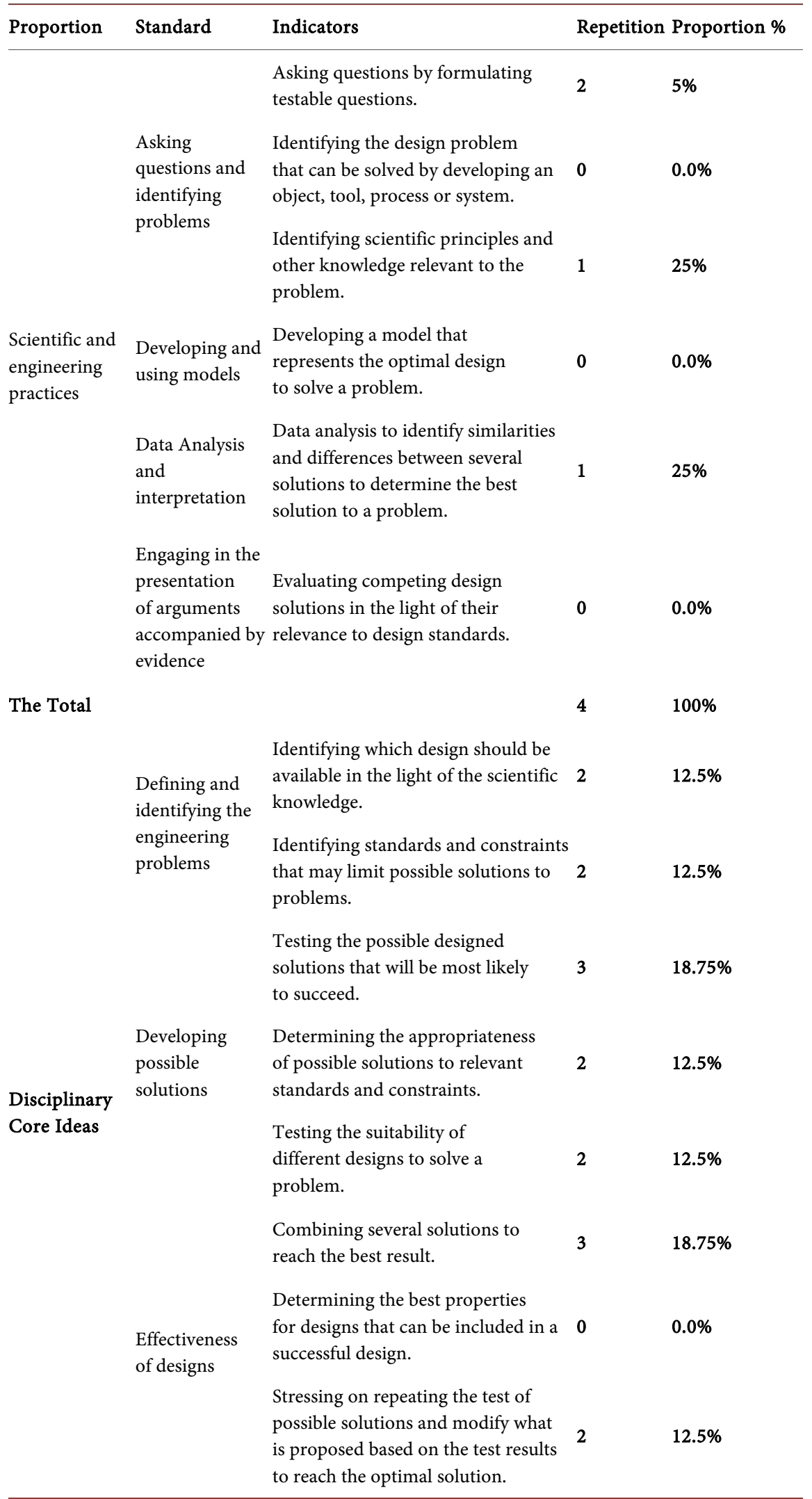




\section{Continued}

\begin{tabular}{|c|c|c|c|}
\hline The Total & & 16 & $100 \%$ \\
\hline $\begin{array}{ll} & \text { The impact } \\
& \text { of science, } \\
\text { Comprehensiveengineering and } \\
\text { concepts } & \text { technology on } \\
& \text { society and the } \\
& \text { natural world }\end{array}$ & $\begin{array}{l}\text { Identifying the negative and positive } \\
\text { results of human activity in the short } \\
\text { and long terms on the environment } \\
\text { and human health. } \\
\text { Identifying technological uses and } \\
\text { their societal and economic impacts. } \\
\text { Identifying scientific principles } \\
\text { relevant to a problem and potential } \\
\text { impacts on individuals and the } \\
\text { natural environment that may limit } \\
\text { possible solutions. }\end{array}$ & & \\
\hline The Total & & 13 & $100 \%$ \\
\hline
\end{tabular}

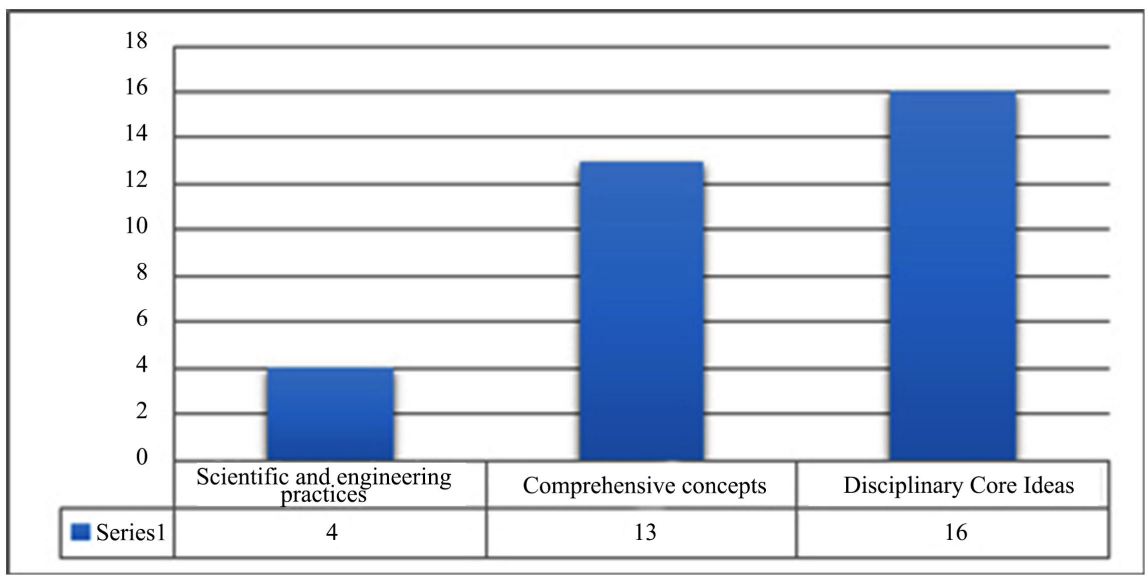

Figure 6. Frequency distributions of the Next Generation Science Standards NGSS in the science courses at the middle stage in the field of life science.

school courses. The greater inclusion of the standards was concentrated in the standards of the disciplinary core ideas, while the inclusion was less in the crosscutting concepts. It is worth noting that the frequency of engineering design standards is the lowest compared to the inclusion of the standards of the natural science, life science, and the field of earth and space science. These results reflected the nature of the contents of the current science textbooks in middle stage according to the engineering design science that needs a greater degree of development and enrichment.

3) Inclusion ratios of standards in the scientific and engineering practices were as follows:

- Asking questions and identifying problems (75\%).

- Developing and using models (0\%).

- Data analysis and interpretation of (25\%).

- Engaging in the presentation of arguments accompanied by evidence (0\%).

Although the distribution of standards in the four components of the scientific and engineering standards was different, it was not sufficient to judge the var- 
iation or consistency of distribution of these standards, given the frequency of standards was very limited (4).

4) The inclusion ratios of standards in the disciplinary core ideas were as follows:

- Definition and identification of the engineering problems (25\%).

- Developing possible solutions (62.5\%).

- The effectiveness of the engineering designs (12.5\%).

It is clear from the distribution of these ratios that the inclusion of standards for disciplinary core ideas in the field of engineering design sciences was uneven in its distribution, most of which focused on the development of solutions. This standard is relatively easier than the two other standards achieved to a lesser extent and they were the definition and identification of the engineering problems and the effectiveness of the engineering designs.

5) The inclusion ratios of standards in the crosscutting concepts were as follows:

Identifying the negative and positive results of human activity in short and long term on the environment and human health (38.46\%).

Identifying the technological uses and their societal and economic impacts (13.08\%). Identifying the scientific principles relevant to a problem and potential impacts on individuals and the natural environment that may limit possible solutions (38.46\%).

According to the method of distribution of the inclusion ratios of the standards of the crosscutting concepts, there was a consistent balance in the distribution of these standards. However, the lack of repetitions of the standards of the crosscutting concepts, which reached eight recurrences only, did not allow a decisive degree of absolute verification of this balance.

A general comment on the results of analysis of the science books content in middle stage of education according to the Next Generation Science Standards

According to the results of the study, Table 6 summarized the distribution ratios of NGSS according to the four analyzed areas.

Table 6. Synthesis of the results of analysis of the science books content in middle stage of education according to the Next Generation Science Standards (NGSS).

\begin{tabular}{|c|c|c|c|c|c|c|c|c|c|c|}
\hline \multirow{3}{*}{$\begin{array}{l}\text { Dimensions of } \\
\text { Analysis }\end{array}$} & \multicolumn{8}{|c|}{ Fields of Analysis } & & \\
\hline & \multicolumn{2}{|c|}{$\begin{array}{l}\text { Field of Natural } \\
\text { Science }\end{array}$} & \multicolumn{2}{|c|}{$\begin{array}{l}\text { Field of Life } \\
\text { Science }\end{array}$} & \multicolumn{2}{|c|}{$\begin{array}{l}\text { Field of Earth } \\
\text { Science }\end{array}$} & \multicolumn{2}{|c|}{$\begin{array}{c}\text { Field of Engineering } \\
\text { Design }\end{array}$} & \multicolumn{2}{|c|}{ Total } \\
\hline & Frequency & $\%$ & Frequency & $\%$ & Frequency & $\%$ & Frequency & $\%$ & Frequency & $\%$ \\
\hline $\begin{array}{c}\text { Scientific and } \\
\text { Engineering Practices }\end{array}$ & & $18.63 \%$ & 22 & $15.49 \%$ & 8 & $16.00 \%$ & 4 & $12.12 \%$ & 64 & $16.58 \%$ \\
\hline $\begin{array}{l}\text { Disciplinary } \\
\text { Core Ideas }\end{array}$ & 81 & $50.31 \%$ & 75 & $52.82 \%$ & 24 & $48.00 \%$ & 16 & $39.39 \%$ & 196 & $50.78 \%$ \\
\hline Crosscutting Concepts & 50 & $31.06 \%$ & 45 & $31.69 \%$ & 18 & $36.00 \%$ & 13 & $48.48 \%$ & 126 & $32.64 \%$ \\
\hline Total & 161 & $100 \%$ & 142 & $100 \%$ & 50 & $100 \%$ & 33 & $100 \%$ & 386 & $100 \%$ \\
\hline
\end{tabular}




\section{The data in the previous table indicated that:}

1) The number of the included standards in the middle stage textbooks and the practical experiences, regardless the field of analysis, was distributed as follows: the largest percentage of inclusion was achieved for the disciplinary core ideas (5.78\%), followed by the crosscutting concepts (32.64\%), and the scientific and engineering practices (16.58\%).

2) In general, there was some consistency between the four areas of analysis in the current study in how the dimensions of the analysis where the next generation science standards (NGSS) were divided. The disciplinary core ideas were the highest in inclusion, followed by the crosscutting concepts, and finally the scientific and engineering practices.

3) The high inclusion percentages of the standards of the disciplinary core ideas in the middle stage science textbooks was reflected according to the next generation science standards (NGSS). These results showed that the nature of the content of the current science textbooks gave a great importance to the cognitive content provided to the learners. This reflected the academic value mixed with investigation thinking whereas the Next Generation Science Standards gave a greater value to the nature of the learner's practices in the applications and problems of life based on academic knowledge and skills.

4) The frequency of the science and engineering design was generally the lowest compared to the frequency of the standards of the other three fields. This reflected the need of the science books in the middle stage to be developed further in this aspect.

5) There was no clear balance in the standards frequency distribution among the four areas of analysis. The greatest share was in the natural science, life science, and doubled in the frequency of standards in the field of earth and space science and the engineering design science.

In general, the results of the current study were in line with the results of the previous studies that showed the need for the development and improvement of the science courses according to the Next Generation Science Standards [8] [10]-[15] [33]. The current study differs from these studies in a very important aspect in which it worked to evaluate the science books in a whole stage and in all dimensions and fields of the Next Generation Science Standards. Research work on one of the fields of science standards does not provide an appropriate opportunity for a comprehensive and in-depth insight into the extent of the standard inclusions and create an integrated vision for development. Especially that the nature of Next Generation Science Standards NGSS is based in its philosophy on the interrelationship between the different fields of science. It is worth mentioning that the previous studies that investigated one of the areas of NGSS focused only on the secondary stage of education. In addition, there are no studies on the middle stage of education, even though this stage represents a major starting point in the formation of the scientific mentality of the learner. It also gives them the skillful preparation of the most specialized scientific study and accurate qualification of the skills of the labor market in the future. 


\section{First phase of development (short term)}

1) Enrichment of the current content of science books in the middle stage through additional educational activities or to replace educational activities with activities that meet the Next Generation Science Standards with respect to the scientific and engineering practices that represent the bulk of NGSS's lack of inclusion.

2) Making an additional guide for teachers on how to implement NGSS standards activities.

3) Conducting training courses for teachers on what is meant by the Next Generation Science Standards, and the technical practices needed by the teacher activities of those standards that have been added as enrichment activities.

4) Focusing on the development of the practical experiences book because it represents a strong opportunity to achieve NGSS by raising the level of hypotheses and practical procedures, and the collection and dissemination of information.

\section{Second phase of development (middle term)}

1) Working on comprehensive and in-depth studies of the analysis of science books in all stages of education in Saudi Arabia (k-12) to find out the reality of incorporating the Next Generation Science Standards NGSS.

2) Developing the content of science courses according to NGSS in a systematic manner. The Next Generation Science Standards are based on the idea of connecting the courses via a framework passing all the stages of education $(k-12)$ with the practical practices and working through a set of standards that describe the practical practices in which learners must be able to do.

3) Development of the science courses according to NGSS should be linked to the vision of the Kingdom of Saudi Arabia in 2030. The vision of the Kingdom was of a practical, industrial and technological nature. It is in line with the thought of Next Generation Science Standards. In a previous study of the researcher about the inclusion extent of the scientific concepts, in accordance with the Kingdom's vision 2013, in the science courses at the middle stage, he revealed a gap between the included concepts in the vision and their inclusion in the science books.

4) Adopting an integrated electronic system to provide the science courses in a systematic manner according to NGSS, so that the learners' knowledge of the targeted practices will be verified through electronic tests for the learners on a regular and continuous basis.

5) Holding extensive training programs for teachers on the Next Generation Science Standards according to the developed content.

6) Linking the teacher preparation courses in the faculties of education to the development of the students' skills on teaching according to the Next Generation Science Standards.

\section{Phase III Development (Long Term)}

Formation of a national committee on the Next Generation Science Standards to supervise and follow up the approved science courses according to Next Generation Science Standards, aims to:

1) Follow-up and evaluate the development of the books content and the standards that are developed according to the changes in knowledge and its applications; this is an important direction regarding the validity of the standards as presented by the developers of the Next Generation Science Standards NGSS.

2) Conduct forward-looking and prospective studies on the expected science standards and practices of the learner in the labor market.

3) Evaluate the performance of learners systematically in the practice of the Next Generation Science Standards.

4) Adopt the talented students to prepare future scientists, especially since the nature of the practices of NGSS focuses on the behavior of scientists and engineers in the study of the variables and their applications.

Figure 7. the proposed vision plan of the current study for the development of the middle stage textbooks according to NGSS.

\section{Answer to the fifth question of the study:}

The fifth question of the study is (What is the proposed vision for the development of the science courses in the middle stage of education in the Kingdom of Saudi Arabia in light of the Next Generation Science Standards NGSS?) The answer to this question was based on the findings of the current study that evaluated the content of the science courses in the middle stage through the fields of (natural science, earth and space science, life science, and science of engineering design) according to the dimensions of the Next Generation Science Standards NGSS. In general, the developed vision proposals were represented in Figure 7. 


\section{Suggestions for Further Research}

1) Conducting studies on evaluating the science courses at all stages of general education in the Kingdom of Saudi Arabia.

2) Effectiveness of enrichment teaching activities on developing the Next Generation Science Standards in different stages of education.

3) Effectiveness of proposed training programs on developing the skills of science teachers in light of the Next Generation Science Standards.

4) Developing the content of the science courses in the light of the scientific and engineering practices of the Next Generation Science Standards (NGSS).

5) Predictive study on the expected science standards in 2050.

\section{Conflicts of Interest}

The author declares no conflicts of interest regarding the publication of this paper.

\section{References}

[1] Best, J. and Dunlap, A. (2017) Next Generation Science Standards: Considerations for Curricula, Assessments, Preparation, and Implementation. Northwest Evaluation Association, McREL International.

[2] Donovan, L., Green, T. and Mason, C. (2014) Examining the 21st Century Classroom: Developing an Innovation Configuration Map. Journal of Educational Computing Research, 50, 161-178. https://doi.org/10.2190/EC.50.2.a

[3] Wilcox, J., Kruse, W. and Clough, P. (2015) Teaching Science through Inquiry. Science Teacher, 82, 62-67. https://doi.org/10.2505/4/tst15_082_06_62

[4] Hassanin, B. (2016) Next Generation Science Standards. Educational Magazine Egypt, 46, 398-439.

[5] Jacobson, M., Taylor, E. and Richards, D. (2016) Computational Scientific Inquiry with Virtual Worlds and Agent-Based Models: New Ways of Doing Science to Learn Science. Interactive Learning Environments, 24, 2080-2108. https://doi.org/10.1080/10494820.2015.1079723

[6] NGSS Lead States (2013) Next Generation Science Standards: For States, by States. National Academies Press, Washington DC.

[7] The Next Generation Science Standards (2013) Development Overview. http://www.nextgenscience.org/development-overview

[8] Slater, S.J. and Slater, T.F. (2015) Questioning the Fidelity of the "Next Generation Science Standards" for Astronomy and Space Sciences Education. Journal of Astronomy \& Earth Sciences Education, 2, 51-64. https://doi.org/10.19030/jaese.v2i1.9277

[9] Krajcik, J. (2013) The Next Generation Science Standards. A Focus on Physical Science. National Science Teachers Association.

[10] Facchini, N. (2014) Elements of the Next Generation Science Standards' (NGSS) New Framework for K-12 Science Education Aligned with STEM Designed Projects Created by Kindergarten, 1st and 2nd Grade Students in a Reggio Emilio, Project Approach Setting. http://search.proquest.com/docview/1545674184

[11] Baz, M. (2017) The Development of the Chemistry Curriculum in the First Grade in the Light of the Field of the Engineering Design of the Next Generation Science 
Standards (NGSS). Education College Journal in Port Said, 22, 1161-1206.

[12] Bybee, R. (2014) NGSS and the Next Generation of Science Teachers. Journal of Science Teacher Education, 25, 211-221. https://doi.org/10.1007/s10972-014-9381-4

[13] Abdul-Karim, S. (2017) NGSS-Based Training Program for the Development of Deep Understanding, the Scientific Investigation Skills and the Scientific Debate among the Primary Stage Science Teachers. Arab Studies in Education and Psychology-Saudi Arabia, 87, 21-111.

[14] Ahmed, N. and Bugmi, M. (2017) Analysis of the Physics Books Content in the Kingdom of Saudi Arabia in the Light of the Next Generation Science Standards NGSS. Jordanian Journal of Educational Sciences-Jordan, 13, 309-326.

[15] Issa, H. and Ragheb, R. (2017) A Proposed Vision of the Development of Geological Education in the Different Educational Stages Based on the Perspective of the Next Generation Science Standards NGSS. Journal of Scientific Education-Egypt, 20, 143-196.

[16] Lee, O., Miller, E. and Januszyk, R. (2014) Next Generation Science Standards: All Standards, All Students. Journal of Science Teacher Education, 25, 223-233. https://doi.org/10.1007/s10972-014-9379-y

[17] Bowman, L.L. and Govett, A.L. (2015) Becoming the Change: A Critical Evaluation of the Changing Face of Life Science, Reflected in the NGSS. Science Educator, 24, 51-61.

[18] Rowaqa, G. (2016) Adopting the Next Generation Science Standards to a Content Design in Genetics at the Eighth Grade in Jordan. Jordanian Journal of Educational Sciences-Jordan, 12, 455-467.

[19] Arab Organization of Education, Culture and Science (2014) Analyzing the Results of the International Assessments TIMSS in 2011 in Arab Countries. Arab Observatory of Education, Education Administration.

[20] Fahidi, H. (2015) Assessment of the Content of the Developed Science Courses in the Kingdom of Saudi Arabia in the Light of the Requirements of Trends in International Mathematics and Science Study (TIMSS). The Conference of Excellence in Teaching and Learning Science and Mathematics I, Science, Technology, Engineering and Mathematics, 5-7 May 2015.

[21] Rubai, M. and Abdul-Majid, M. (2010) Induction of the Science Books in the Primary Stage in Saudi Arabia. Journal of Scientific Education-Egypt, 13, 1-26.

[22] Bogus, N. (2011) Awareness with the Symbols of Danger and Methods of Prevention in the New Science Books in Saudi Arabia. Journal of Security Research, Saudi Arabia, 20, 134-177.

[23] Ruwaythi, I. (2016) Health Education in the Content of Science Books at the Top three Grades of the Primary Stage in the Kingdom of Saudi Arabia. Studies in Curriculum and Teaching Methods-Egypt, 214, 15-90.

[24] Otaibi, W. (2013) Scientific Values of Citizenship in the Content of Science Books at the Middle Stage of Education in Saudi Arabia, an Analytical Study. Journal of Education, 153, 127-177.

[25] Muzaini, T. (2017) The Inclusion Extent of the Theory of Multiple Intelligences in Science Books at the Middle Stage in Saudi Arabia. Studies in Curriculum and Teaching Methods-Egypt, 221, 68-109.

[26] Mohammed, H. (2015) Effectiveness of the Differentiated Teaching Approach in Teaching Science on Developing the Scientific Concepts and the Trend towards Science among Primary School Students in Saudi Arabia. Journal of Scientific Education, 18, 2019-2256. 
[27] McGee, S. and Nutakki, N. (2017) The Impact of Adapting a General Professional Development Framework to the Constraints of In-Service Professional Development on the Next Generation Science Standards in Urban Settings. Journal of Urban Learning, Teaching, and Research, 13, 73-89.

[28] Comas, W.F. and Nouri, N. (2016) The Nature of Science and the Next Generation Science Standards: Analysis and Critique. Journal of Science Teacher Education, 27, 555-576. https://doi.org/10.1007/s10972-016-9474-3

[29] The Next Generation Science Standards (2014) Lead State Partners. http://www.nextgenscience.org/lead-state-partners

[30] The Next Generation Science Standards (2013) Development Process. http://www.nextgenscience.org/developmentprocess

[31] Brownstein, E.M. and Horvath, L. (2016) Next Generation Science Standards and edTPA: Evidence of Science and Engineering. Electronic Journal of Science Education, 20, 44-62.

[32] Smith, J. and Nadelson, L. (2017) Finding Alignment: The Perceptions and Integration of the Next Generation Science Standards Practices by Elementary Teachers. School Science and Mathematics, 117, 194-203. https://doi.org/10.1111/ssm.12222

[33] Harris, K., Sithole, A. and Kibirige, J. (2017) A Needs Assessment for the Adoption of Next Generation Science Standards (NGSS) in K-12 Education in the United States. Journal of Education and Training Studies, 5, 54-62.

https://doi.org/10.11114/jets.v5i9.2576 